\begin{tabular}{|l|l|}
\hline \multirow{2}{*}{$\begin{array}{l}\text { INTERNATIONAL } \\
\text { ENGINEERING, } \\
\text { SCIENCE AND } \\
\text { EDUCATION } \\
\text { GROUP }\end{array}$} & $\begin{array}{l}\text { Middle East Journal of Science } \\
(2017) \text { 3(1): } 20-25\end{array}$ \\
INESEG & doi: $10.23884 /$ mejs.2017.3.1.03 \\
ISSN: $2536-5312$
\end{tabular}

\title{
KINETICS OF ADSORPTION OF ACID RED 1 ONTO CHITOSAN AND CROSS-LINKED CHITOSAN FROM AQUEOUS SOLUTION
}

\author{
Ayfer Yildirim ${ }^{* 1}$, Yasemin Bulut ${ }^{2}$ \\ ${ }^{* 1}$ Mardin Artuklu University, Vocational Higher School of Healthcare Studies,47060 Mardin/Turkey \\ ${ }^{2}$ Dicle University, Faculty of Sciences, Department of Chemistry,21280 Diyarbakır/Turkey \\ *ayferfirtla@yahoo.com

\begin{abstract}
Chitosan(CS) and crosslinked-Chitosan (CCS) (Chitosan+Glutaraldehite) were utilized as adsorbents to remove acid red1(ARI) from aqueous solution by adsorption. Batch experiments were conducted to study initial concentration of adsorbate and temperature on dye adsorption. The kinetic data obtained from different batch experiments were analyzed using pseudo first-order and pseudo second-order and Weber-Morris equations, and the rate constants of first-order adsorption (kpf), the rate constants of secondorder adsorption (kps) and intraparticle diffusion rate constants (kid) at these concentrations and temperatures were calculated, respectively.
\end{abstract}

Key words: chitosan, adsorption, acid red1

\section{Introduction}

Water pollution by dyes that affect human health by their carcinogenic and mutagenic properties; through the discharge of industrial effluents is a worldwide environmental problem. Adsorption using low-cost adsorbents is one of the most economically and viable method for dyeing wastewater decontamination.

Chitosan, a natural polymer that can be obtained from crab shells, shrimps and insects is be an excellent biosorbent for removal of metal ions and dyes from wastewaters. The main advantages of chitosan sorbents are their nontoxicity, high efficiency,biodegradability and low cost [1-3]. Chitosan possesses various functional groups in its structure such as amine, hydroxyl and acetamide group that can be involved in sorption process. However, chitosan still has some drawbacks such as lower stability that is a result of its hydrophillicity nature and $\mathrm{pH}$ sensitivity. Various chitosan based composites have been designed to overcome these problems. Integration of an adsorbent with other materials through methods such as grafting, impregnation, chelation and crosslinking has better adsorption properties than the individual components effects [4-6]. Composite adsorbents can be prepared with the sole aim of 
enhancing their selectivity, regeneration, surface area, mechanical strength and surface chemistry amongst others.

\section{Results And Findings}

\subsection{Effects of Initial Dye Concentration}

Effects of initial dye concentration results for AR1 sorption on CSC are plotted in Fig. 2. Data shows increasing in sorption of AR1 with an increasing in the initial dye concentration (Co) from 50 to 200 mgL-1.The sme results has founded in reactive red 120 adsorption onto chitosan-Fe(III)-crosslinked [7-8]. Adsorption increases rapidly at the beginning than, adsorption increses gradually and finally, the equilibrium state indicates that the adsorbent reached saturation. Therefore, the highest adsorption capacity is found at concentration of $200 \mathrm{mgL}-1$.The adsorption equilibrium was reached after $6 \mathrm{~h}$ depending on the initial dye concentration (Fig.1 and Fig.2).

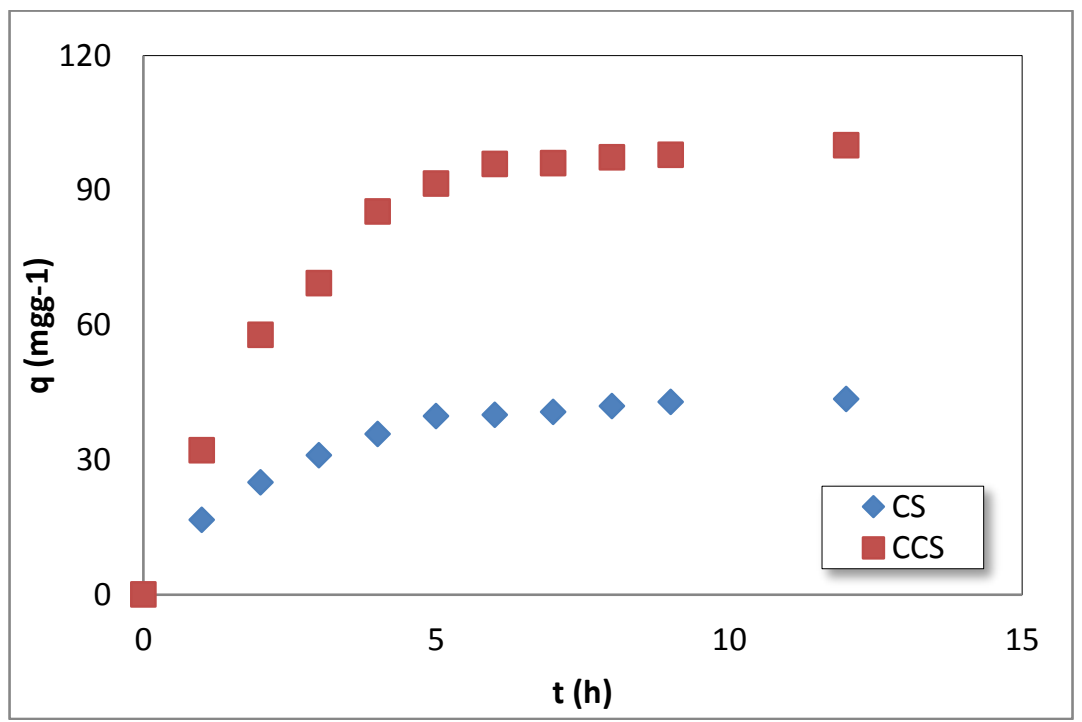

Figure 1. Adsorption Capacity of AR1 with Chitosan (CS) and Crosslinked-Chitosan (CCS)

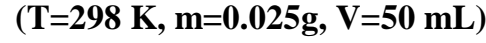




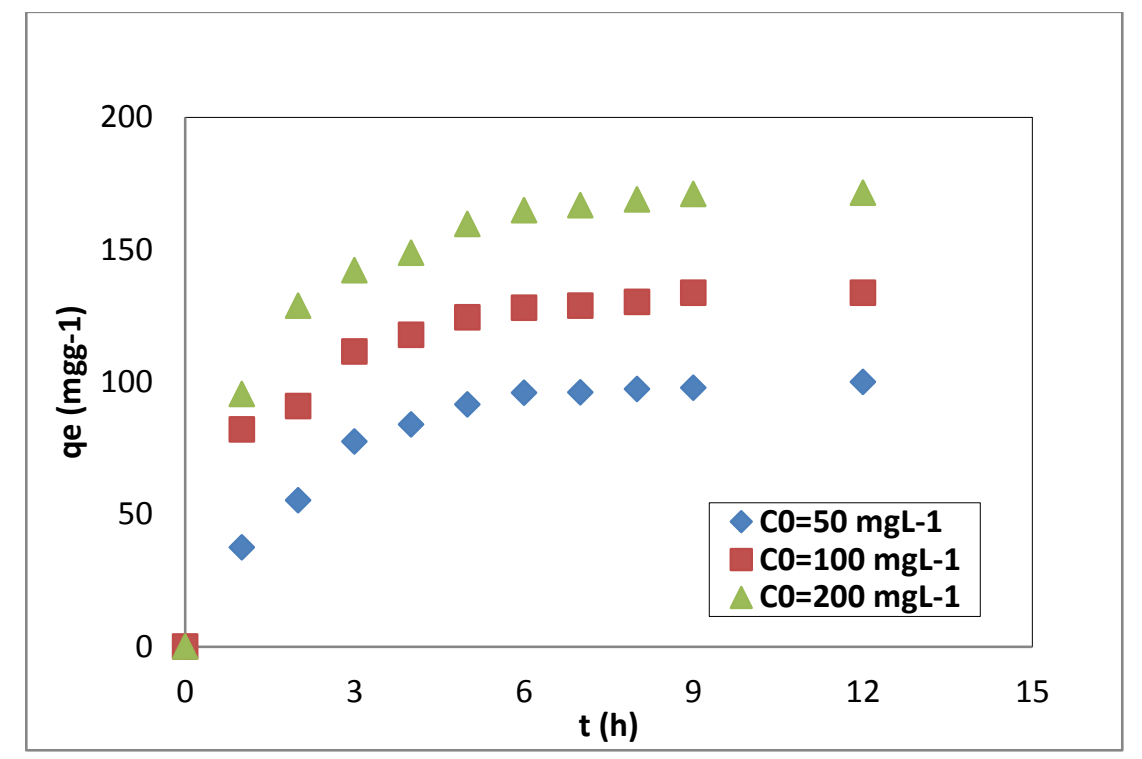

Figure 2. Influence Initial Dye Concentration on Adsorption of AR1 on CCS

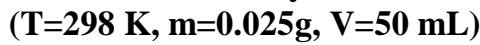

\subsection{Adsorption Kinetics}

The kinetics behavior of adsorption process were studied with $298 \mathrm{~K}$, three different initial concentration $(50,100,200 \mathrm{mgL}-1)$ and initial concentration $100 \mathrm{mgL}-1$, three different temperatures $(298,308,318$ K) (Fig.3 and Fig.4). In order to examine the control mechanisms of adsorption process of dye, several kinetic models were used for experimental data. The pseudo-firs-order, pseudo-second-order and intraparticle models were used and constants of these models were calculated (Table 1). According to Table 1, it can be observed that in all initial concentrations and temperatures pseudo-second-order show a good fit with experimental data (R2>0.99).
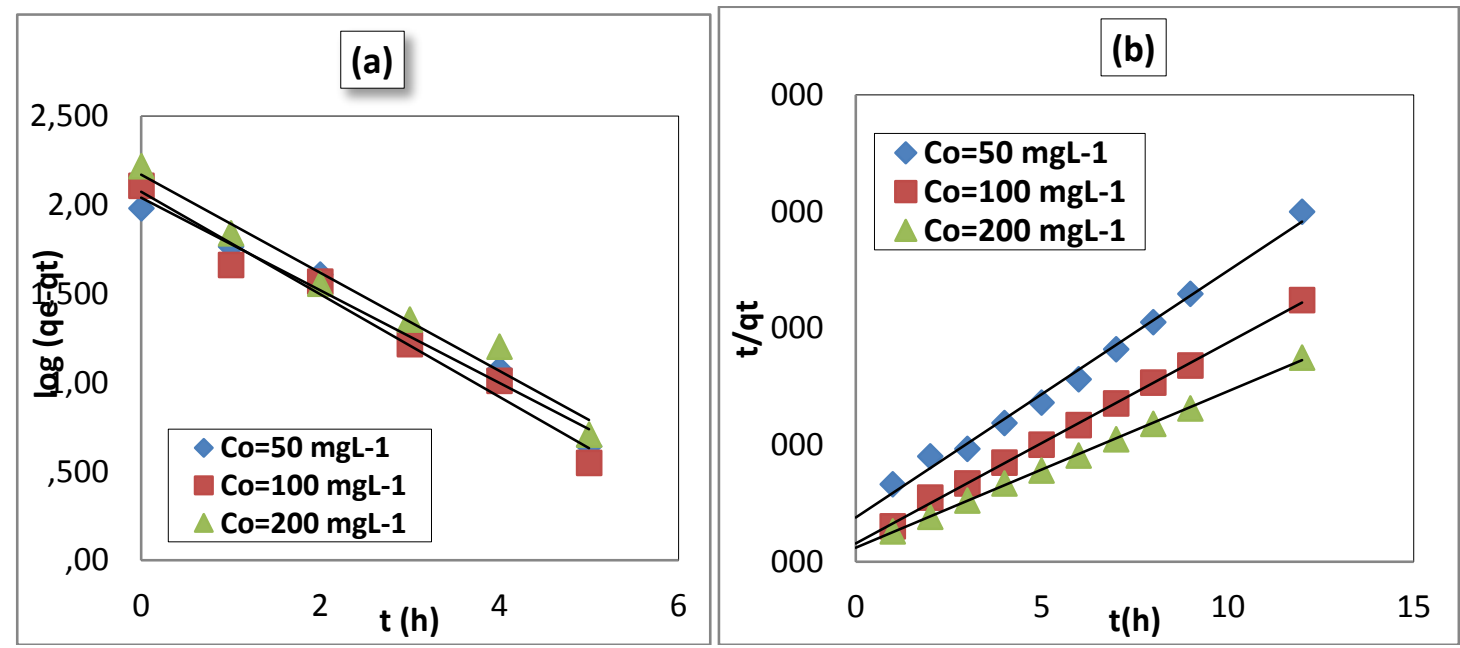


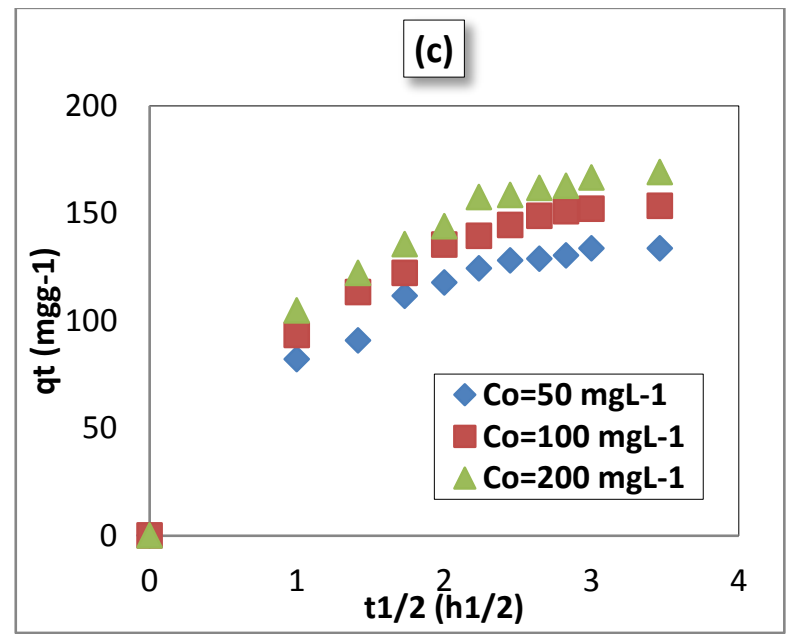

Figure 3. (a) Pseudo-first-order, (b) pseudo-second-order and (c) intraparticle diffusion kinetic plots of AR1

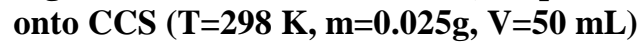

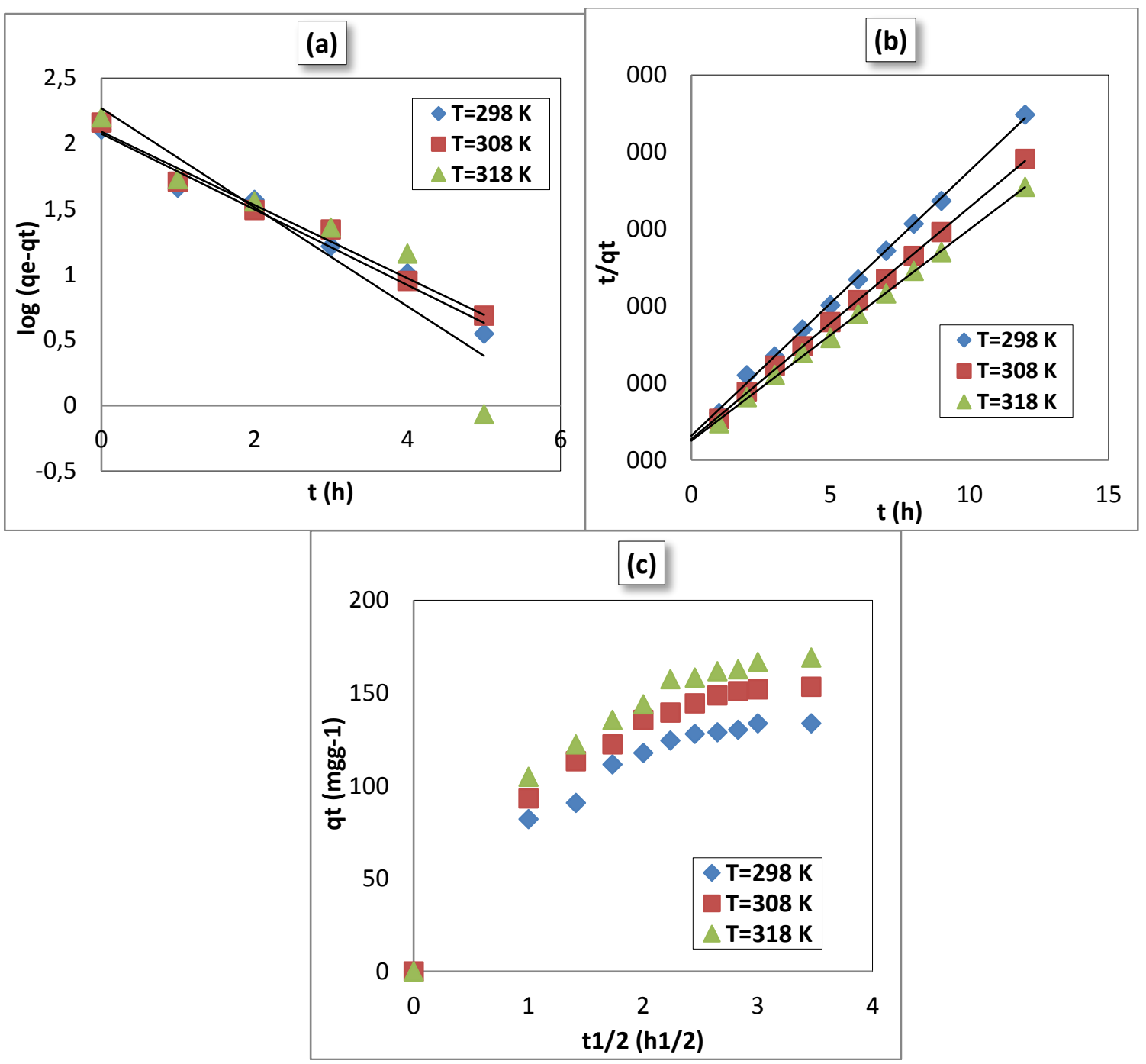

Figure 4. (a) Pseudo-first-order, (b) pseudo-second-order and (c) intraparticle diffusion kinetic plots of AR1 onto CCS $\left(\mathrm{Co}=100 \mathrm{mgL}^{-1}, \mathrm{~m}=0.025 \mathrm{~g}, \mathrm{~V}=50 \mathrm{~mL}\right)$ 
Table 1. Kinetics Parameters of the Dye AR1 by the CCS

\begin{tabular}{|c|c|c|c|c|}
\hline \multirow{2}{*}{ Model } & \multirow{2}{*}{ Coefficients } & \multicolumn{3}{|c|}{$\mathrm{Co}\left(\mathrm{mgL}^{-1}\right)$} \\
\hline & & 50 & 100 & 200 \\
\hline \multirow{3}{*}{$\begin{array}{l}\text { Pseudo-first- } \\
\text { order }\end{array}$} & $\mathrm{q}_{\mathrm{e}}\left(\mathrm{mgg}^{-1}\right)$ & 109.80 & 118.55 & 147.94 \\
\hline & $\mathbf{k}_{\mathrm{pf}}\left(\mathrm{dak}^{-1}\right)$ & 0.60 & 0.66 & 0.64 \\
\hline & $\mathbf{R}^{2}$ & 0.9783 & 0.9756 & 0.9746 \\
\hline \multirow{3}{*}{$\begin{array}{r}\text { Pseudo- } \\
\text { second-order }\end{array}$} & $q_{e}\left(\mathbf{m g g}^{-1}\right)$ & 119.05 & 144.93 & 185.19 \\
\hline & $\mathbf{k}_{\mathrm{ps}}$ & 65.79 & 158.73 & 208.33 \\
\hline & $\mathbf{R}^{2}$ & 0.9915 & 0.9986 & 0.9993 \\
\hline \multirow{4}{*}{ Intraparticle } & $\mathbf{k}_{\text {id }}\left(\mathrm{mgg}^{-1} \mathbf{t}^{-}\right.$ & 12.94 & 12.63 & 13.38 \\
\hline & $\mathbf{R}^{2}$ & 0.9617 & 0.9424 & 0.9289 \\
\hline & & \multicolumn{3}{|c|}{$\mathbf{T}(\mathbf{K})$} \\
\hline & & 298 & 308 & 318 \\
\hline \multirow{3}{*}{$\begin{array}{l}\text { Pseudo-first- } \\
\text { order }\end{array}$} & $q_{\mathrm{e}}\left(\mathrm{mgg}^{-1}\right)$ & 118.55 & 122.94 & 185.65 \\
\hline & $\mathbf{k}_{\mathrm{pf}}\left(\mathbf{d a k}^{-1}\right)$ & 0.66 & 0.64 & 0.87 \\
\hline & $\mathbf{R}^{2}$ & 0.9584 & 0.9197 & 0.9843 \\
\hline \multirow{3}{*}{$\begin{array}{l}\text { Pseudo- } \\
\text { nd-order }\end{array}$} & $q_{\mathrm{e}}\left(\mathrm{mgg}^{-1}\right)$ & 158.73 & 185.19 & 200.00 \\
\hline & $\mathbf{k}_{\mathbf{n s}}$ & 3.18 & 4.29 & 5.15 \\
\hline & $\mathbf{R}^{2}$ & 0.9986 & 0.9992 & 0.9991 \\
\hline \multirow{2}{*}{ Intraparticle } & $\mathbf{k}_{\text {id }}\left(\mathrm{mgg}^{-1} \mathbf{t}^{-}\right.$ & 12.93 & 12.63 & 13.38 \\
\hline & $\mathbf{R}^{2}$ & 0.9617 & 0.9424 & 0.9289 \\
\hline
\end{tabular}

\section{Conclusion}

In the present work, CCS composite was prepared at optimum conditions by ionic gelation method for adsorption of AR1. Adsorption of AR1onto CCS composite was better than chitosan. Likewise, the use of crosslinking agent makes available to improve the dissolubility of chitosan composites in acidic medium. The kinetic results show that the pseudo-second-order model best followed with correlation coefficients (R2>0.99). Activation energy (Ea) is found $19.05 \mathrm{~kJ} / \mathrm{mol}(<20 \mathrm{~kJ} / \mathrm{mol})$, so adsorption of AR1 onto CCS is physisorption. 


\section{References}

[1] Auta, M., Hameed, B.H. (2014) . Chitosan-clay composite as highly effective and low-cost adsorbent for batch andfixed-bed adsorption of methylene blue. Chemical Engineering Journal. $237,352-361$

[2] Demarchi, C.A., Campos, M., Rodrigues, C.A.(2013). Adsorption of textile dye Reactive Red 120 by the chitosan-Fe(III)-crosslinked: Batch and fixed-bed studies. Journl of Environmental Chemical Engineering, 1, 1350-1358.

[3] Liu, Y., Zheng, Y., Wang, A. (2010). Enhanced adsorption of Methylene Blue from aqueous solution bychitosan-g-poly (acrylic acid)/vermiculite hydrogel composites. Journal of Environmental Science, 22(4) 486-493

[4] Wang, L., Han, B., Wang, Z., Dai, L., Zhou, H., Li, Y., \& Wang, H. (2015). Effective improvement of sensing performance of amperometric NO2 sensor by Ag-modified nanostructured $\mathrm{CuO}$ sensing electrode. Sensors and Actuators B: Chemical, 207, Part A(0), 791-800. doi:http://dx.doi.org/10.1016/j.snb.2014.10.125

[5] Yan, X., Hu, D., Li, H., Li, L., Chong, X., \& Wang, Y. (2011). Nanostructure and optical properties of $\mathrm{M}$ doped $\mathrm{ZnO}(\mathrm{M}=\mathrm{Ni}, \mathrm{Mn})$ thin films prepared by sol-gel process. Physica $\mathrm{B}$ : Condensed Matter, 406(20), 3956-3962. doi:http://dx.doi.org/10.1016/j.physb.2011.07.037

[6] Yang, C., Su, X., Xiao, F., Jian, J., \& Wang, J. (2011). Gas sensing properties of CuO nanorods synthesized by a microwave-assisted hydrothermal method. Sensors and Actuators B: Chemical, 158(1), 299-303. doi:http://dx.doi.org/10.1016/j.snb.2011.06.024

[7] Yildiz, A., Horzum, Ş., Serin, N., \& Serin, T. (2014). Hopping conduction in In-doped CuO thin films. Applied Surface Science, 318(0), 105-107. doi:http://dx.doi.org/10.1016/j.apsusc.2014.01.118

[8] Zhang, Y., Liu, Z., Zang, D., \& Feng, L. (2014). Structural and opto-electrical properties of CuAl-O thin films prepared by magnetron sputtering method. Vacuum, 99(0), 160-165. doi:http://dx.doi.org/10.1016/j.vacuum.2013.05.019 